\title{
Using Skeletal Outlines and Illustrative Diagrams as a Teaching/Learning Strategy in a Baccalaureate Nursing Pharmacology Course
}

\author{
${ }^{1} \mathrm{C}$. McMillan Boyles, ${ }^{2} \mathrm{C}$. Duncan
}

${ }^{1 .} \mathrm{RN}, \mathrm{BScN}, \mathrm{MScN}$, School of Nursing, Laurentian University.

2. RN, BScN, MN, PhD, School of Nursing, Laurentian University.

\begin{abstract}
Knowledge of pharmacology is an important aspect of safe, effective and competent clinical nursing practice, yet it can be challenging to teach. Many academics within the discipline of nursing are concerned that current nursing curricula may not be preparing nurses to accept responsibilities related to pharmacological management and are inadequately prepared for their role in medication administration. Nursing faculty who teach advanced clinical nursing practice courses also report that students lack the foundational knowledge of pharmacology needed and required in advanced clinical courses. These concerns have led to a call for additional focus that must be placed on student knowledge acquisition of pharmacology content due to poor student performance on standardized tests. Within a four-year undergraduate Bachelor of Science in Nursing $(\mathrm{BScN})$ curriculum, pharmacology content was taught to first-term, second year students within a nursing praxis course, over a 13 -week period. Students were required to understand the foundational principles, concepts and content of pharmacology and to integrate this knowledge in a critical reflective manner in clinical practice. A teaching/learning approach was implemented within the classroom that aligned with the work of Bui and McDaniel (2015). This method utilized outlines, illustrative diagrams and mental models aimed to enhance student note-taking in the development of content knowledge and to assist students to internalize critical cognitive learning processes. Consequently, student comprehension and critical thinking of pharmacology content was increased. Establishing a solid foundation of pharmacology that is integrated in a critically manner is a major component of providing safe and competent patient care.
\end{abstract}

Keywords: nursing education, pharmacology, undergraduate, illustrative diagrams, note-taking

\section{References}

Bui, D.C. \& McDaniel, M.A. (2015). Enhancing learning during lecture note-taking using outlines and illustrative diagrams. Journal of Applied Research in Memory and Cognition 4, 129-135. doi: http://dx.doi.org/10.1016/j.jarmac.2015.03.002

King, R.L. (2004). Nurses' perception of their pharmacology educational needs. Journal of Advanced Nursing 45(4), 392-400. doi: 10.1046/j.1365-2648.2003.02922.x

Lim, A.G. \& Honey, M. (2006). Integrated undergraduate nursing curriculum for pharmacology. Nurse Education in Practice 6(3), 163-168. doi:10.1016/j.nepr.2005.11.005

Manias, E. \& Bullock, S. (2002). The educational preparation of undergraduate nursing students in pharmacology: perceptions and experiences of lecturers and students. International Journal of Nursing Studies 39(7), 757-769. PII:S0020-7489(02)00018-4 